\title{
Formação Continuada de Professores Através de Comunidades de Prática: um Estudo de Caso
}

\author{
Title: Continuing Teacher Training Through Communities of Practice: a case study
}

\author{
Karen Selbach Borges \\ Instituto Federal de Educação, Ciência \\ e Tecnologia do Rio Grande do Sul \\ Rua Cel. Vicente 281 - Porto Alegre - \\ Rio Grande do Sul \\ karen.borges@poa.ifrs.edu.br
}

\author{
Aline Grunewald Nichele \\ Instituto Federal de Educação, Ciência \\ e Tecnologia do Rio Grande do Sul \\ Rua Cel. Vicente 281 - Porto Alegre - \\ Rio Grande do Sul \\ aline.nichele@poa.ifrs.edu.br
}

\author{
Crediné Silva de Menezes \\ Universidade Federal do Rio \\ Grande do Sul \\ Av. Paulo Gama 11- Porto Alegre \\ - Rio Grande do Sul \\ credine@gmail.com
}

\begin{abstract}
Resumo A formação continuada de professores é requisito para um sistema de educação de qualidade. Todavia, o formato escolhido para este processo nem sempre consegue atingir todos os docentes de uma instituição de ensino. Há ainda situações, os professores sentem necessidade de aprofundar os temas trabalhados, mas não encontram um espaço para desenvolver esta atividade. É com base neste cenário que apresentamos a formação de comunidades de prática (CoP) como um importante recurso de interação entre os docentes, possibilitando a comunicação, a troca de experiências, a realização colaborativa de atividades e a atualização profissional. De modo a ilustrar esta exposição, apresentamos um estudo de caso de uma Comunidade de Prática em Inovação e Educação no Instituto Federal de Educação, Ciência e Tecnologia do Rio Grande do Sul (IFRS), Campus Porto Alegre. As conclusões desse experimento apontam para a importância de uma mudança de posição do professor em relação à sua formação continuada.
\end{abstract}

Palavras-Chave: formação continuada de professores, comunidades de prática

\begin{abstract}
Continuing teacher training is necessary for a quality education system. However, the format chosen for this process doesn't always reach all teachers of an educational institution. Moreover there are situations where teachers want to deepen some themes but don't find a space to develop this activity. Based on this scenario we present the communities of practice (CoP) as an important feature of interaction between teachers, developing communication, exchange of experiences, collaborative implementation of activities and professional development. In order to illustrate, we present a case study of a Community of Practice in Innovation and Education at the Federal Institute of Education, Science and Technology of Rio Grande do Sul, Porto Alegre Campus. The conclusions of this experiment point to the importance of a position change of the teacher in relation to his continued education.
\end{abstract}

Keywords: continuing teacher training, communities of practice 


\section{Introdução}

Não nascemos prontos. Nem como pessoas, muito menos como profissionais. Considerando que vivemos em um mundo globalizado, em que as empresas contratam pessoas independente de nacionalidade, a disputa pelas vagas de trabalho é cada vez mais acirrada. As pessoas trocam de função, de empresa e até mesmo de área com mais frequência, o que demanda aprender a lidar com novas tecnologias e novos processos, necessários para a solução de problemas cada vez mais complexos.

Entretanto, a academia não prepara os futuros profissionais de forma adequada para enfrentar esse "redemoinho de mudanças, ameaças e oportunidades incontroláveis" [4] . Assim, a formação profissional requer investimentos constantes e, numa realidade em que a globalização e a cultura digital são dominantes, o investimento na atualização e formação continuada é essencial.

Preocupa-nos, em especial, o caso daqueles cuja profissão é preparar os futuros profissionais. Conforme Nóvoa [14], além de formadores estes também são formandos, e como formadores se faz necessária, além do aprimoramento nos conteúdos e técnicas relativas a cada atividade profissional, a constante atualização em relação ao mundo digital. Espera-se que o professor de ensino profissional tenha, por exemplo, habilidade para utilizar ferramentas computacionais, para trabalhar com tecnologias móveis e para interagir com alunos e colegas utilizando redes sociais. Além disso, é desejável que o professor tenha competência para produzir conteúdo, para inovar em suas práticas docentes e para buscar novos conhecimentos.

Sabe-se que é de praxe a oferta de seminários de atualização docente por parte da maioria das instituições de ensino. Entretanto, estes espaços não são suficientes. É preciso que as discussões possam ser estendidas e que os temas trabalhados possam ser expandidos conforme diferentes situações se apresentem durante a prática docente. Neste contexto, a formação de uma comunidade de prática $(\mathrm{CoP})$ se mostra como um importante recurso de interação entre os docentes, a qual possibilitará a comunicação, a troca de experiências, a realização colaborativa de atividades e a atualização profissional.

Através deste artigo, pretende-se fazer uma análise sobre o papel das comunidades de prática como suporte para a formação continuada docente e apresentar um exemplo de experiência focada na educação profissional, com o suporte de ambientes virtuais. Dessa forma, a seção 2 abordará o tema comunidades de prática, a seção 3 apresentará opções de sistemas colaborativos e requisitos para a construção de um habitat digital, a seção 4 tratará sobre a importância da formação continuada de professores e o papel das comunidades de prática neste cenário e a seção 5 descreverá a experiência realizada dentro do Instituto Federal de Educação, Ciência e Tecnologia do Rio Grande do Sul (IFRS), campus Porto Alegre. Na seção 6 são apresentadas as conclusões obtidas a partir desta experiência. A seção 7 traz as considerações finais

\section{Comunidades de Prática}

Uma comunidade de prática é formada por um grupo de indivíduos que compartilham objetivos em comum, um conjunto de problemas ou o interesse em um tema específico, que se reúne para realizar objetivos individuais e do grupo. Essas comunidades conectam pessoas, permitem o diálogo, estimulam a aprendizagem, reúnem e compartilham conhecimento, promovem o trabalho colaborativo, auxiliam os indivíduos a se organizar, gerando novos conhecimentos [2]. Dentro de uma CoP, os participantes tendem a se agrupar de forma a definir três níveis de participação [16]:

- Grupo central: composto por 10 a $15 \%$ dos integrantes. É o grupo encarregado das tomadas de decisão (como lançamento de novos temas e desafios) e da condução dos projetos.

- Grupo ativo: composto por 15 a $20 \%$ dos integrantes. É o grupo que possui participação efetiva na realização das atividades propostas.

- Grupo periférico: composto pela maioria dos integrantes. Participam raramente das discussões; sua atuação é basicamente observar as interações entre os integrantes do grupo central e acompanhar o desenvolvimento das atividades do grupo ativo.

As atividades desenvolvidas dentro de uma CoP frequentemente focam em compartilhar boas práticas e criar novos conhecimentos para melhorar uma prática profissional. Logo os fatores determinantes no sucesso de uma CoP são [6,7]:

- Prática: é definida em função de um "repertório compartilhado" [18], ou seja, os membros da CoP tem, não apenas um trabalho em comum, mas também métodos, ferramentas, linguagens e padrões de comportamento. $\mathrm{O}$ trabalho realizado pode se dar em diferentes campos de prática [9], tais como casos, projetos, problemas, simulações, entre outros, resultando em estudos de caso, artigos, metodologias, padrões, produtos, históricos, etc. 
- Mediação: segundo Mengalli [11] os mediadores são os responsáveis por evitar a evasão e a mudança de interesses em relação ao projeto inicial. Além disso, pode-se dizer também que a mediação é a responsável pelo ritmo da comunidade, ou seja, acompanha o andamento das atividades, auxilia na solução de problemas, apresenta novos desafios e encoraja a participação na comunidade.

- Ambiente: os ambientes dão suporte às interações entre os membros da comunidade. Eles definem se as comunidades serão "presenciais" ou "virtuais". As comunidades virtuais de prática (CoPV) são aquelas que fazem uso da tecnologia digital (TD). As TDs podem melhorar significativamente a comunicação, o compartilhamento de informação e a produção do conhecimento, por meio da adoção de ferramentas de comunicação e acesso à informação por pesquisas e buscas em repositórios e páginas da internet.

Numa CoPV o acesso à informação e a produção de conhecimento também se dá por fontes externas à da própria comunidade, em situações características do convívio digital virtual, como o compartilhamento de links, materiais e opiniões de fora da comunidade [17]. Assim, há a necessidade de se organizar estas informações de modo que ela fique acessível a todos os membros da comunidade, independentemente desta ser presencial ou virtual. Para isso, pode-se recorrer ao uso de sistemas de informação próprios para apoiar atividades colaborativas.

\section{Sistemas Colaborativos}

As tecnologias que serão utilizadas para apoiar uma CoP podem ser variadas e dependerão da proposta e do objetivo da comunidade. Além de ferramentas para comunicação, as CoPs precisam de um ponto de referência; um lugar onde seja possível realizar encontros, promover exposições, disponibilizar um repositório de documentos e referências de pesquisa. Ao oferecer estes recursos através das redes de computadores, seja inter ou intranet, surgem o chamados habitats digitais. Moretto [13] afirma que estes espaços "promovem o trabalho colaborativo, possibilitam o armazenamento e a organização da informação que é distribuida e promovem a comunicação entre os usuários."

As opções tecnológicas para a criação de habitats digitais são bastante variadas e a escolha adequada irá depender da natureza da comunidade, ou seja, se o foco das atividades estará na produção de conteúdo, no desenvolvimento de um projeto ou na interação entre seus membros [5]. O quadro 1 apresenta algumas plataformas de código aberto ou gratuitas, adequadas a cada contexto:

Quadro 1 - Opções de plataformas

\begin{tabular}{l|l|l}
\hline $\begin{array}{c}\text { Produção de } \\
\text { conteúdo }\end{array}$ & $\begin{array}{c}\text { Desenvolvimento de } \\
\text { projetos }\end{array}$ & $\begin{array}{c}\text { Interação } \\
\text { social }\end{array}$ \\
\hline $\begin{array}{l}\text { Wordpress } \\
\text { Blogger } \\
\text { TikiWiki } \\
\text { Joomla } \\
\text { OpencMS }\end{array}$ & $\begin{array}{c}\text { Corais } \\
\text { eXo Community }\end{array}$ & Facebook \\
Muodle & & EdModo \\
PBWorks & &
\end{tabular}

Seja qual for a plataforma escolhida para constituir o habitat digital de uma $\mathrm{CoPV}$, é importante que estejam presentes os seguintes recursos:

- Perfil: onde cada membro da comunidade pode disponibilizar informações a respeito da sua formação, áreas de interesse e atividades nas quais está envolvido.

- Comunicação: seja ela síncrona ou assíncrona, a presença de ferramentas de comunicação é fundamental. Podem ser ferramentas de email, chat e vídeoconferência, para plataformas fixas ou móveis.

- Produção colaborativa de conteúdo: nesta categoria as opções são diversas: ferramentas de escritório "na nuvem", wikis e blogs; mapas mentais e whiteboards virtuais, entre outros.

- Repositório de conteúdo: deve ser capaz de armazenar diversos tipos de mídias, além de endereços web. Além disso, é desejável que o repositório escolhido ofereça funcionalidades básicas de gerenciamento e localização de conteúdo.

- Gerenciador de atividades: tais como agendas e calendários. Listas e quadros de tarefas podem ser interessantes caso a comunidade esteja envolvida em um projeto colaborativo.

- Pesquisas e enquetes: são recursos importantes para as tomadas de decisão.

É importante, também, que as ferramentas escolhidas atendam aos critérios básicos de boa usabilidade, tais como interfaces auto-explicativas, sistemas de ajuda, facilidade de navegação, possibilidade de reverter operações, e configuração conforme as preferências (ou necessidades) do usuário. 


\section{Comunidades de Prática Docente e a Formação Continuada de Profes- sores}

Um dos grandes desafios da profissão professor é manter-se atualizado com as transformações que ocorrem na sociedade, de forma continuada. Algumas dessas modificações ocorrem no que diz respeito aos conteúdos específicos das disciplinas, outras na concepção de mundo, que de vez em quando é oxigenada pelo aporte de novas formas de ver e encarar o trabalho, a economia, o lazer, a vida em sociedade. A todas estas mudanças o professor precisa estar atento para que possa viver em sintonia com o que pensam e dizem seus alunos. E claro, com o que a sociedade espera da formação de seus cidadãos.

Nos dias de hoje, uma das questões que muito incomoda os professores é o uso das tecnologias digitais como mediadora dos processos de aprendizagem. Durante muito tempo a escola e os professores ficaram presos à uma concepção de transmissão do conteúdo, onde os alunos tinham pouca participação nas aulas, que eram limitadas por horários, os chamados "períodos de aula". Neste modelo, as tecnologias serviam apenas para ajudar o professor a transmitir o conteúdo.

Durante este período, o compartilhamento de práticas era muito dependente da engenhosidade dos professores de prepararem materiais físicos e não ocorria com frequência em função da pouca necessidade de construí-los. Com o advento dos materiais digitais, esse compartilhamento ficou mais fácil mas, ainda é pouco o que se observa de trocas. Uma outra particularidade é que, com a revolução provocada pela internet, onde as interações entre indivíduos se intensificaram, abordagens teóricas sobre aprender foram pouco exploradas em função das dificuldades inerentes aos meios de comunicação disponíveis.

Nesse contexto, onde a utilização das TDs ainda é uma barreira a ser superada, surgiram várias propostas de formação docente, oferecidas de forma padronizada, desenvolvidas e ministradas por especialistas. Conforme Imberón [10] esses "treinamentos" não apresentam os resultados desejados, pois os contextos educativos são diversos. "Em primeiro, encontramos diversas tipologias de professorado. Em segundo, um desempenho profissional diversificado com desenvolvimentos profissionais especificos. Em terceiro, a zona de trabalho: rural, semirural, urbana, na periferia e o clima de trabalho dentro do centro educativo. Estas características pessoais e os diversos interesses que eles comportam configuram uma série de elementos que tanto podem favorecer a formação como obstaculizá-la mediante o surgimento de certas resistências. "
Além disso, neste formato de capacitação, o professor assume o tradicional, e criticado, papel de aluno "receptor de informações", pois é o especialista, ministrante do curso, quem seleciona os conteúdos, determina a forma de abordagem e desenvolve as atividades que visam transmitir o conhecimento necessário.

Para que se obtenha os resultados desejados, o professor deve estar ativamente envolvido no processo de formação, pois é ele o sujeito sobre o qual são depositadas todas as expectativas. Nóvoa [15] afirma: "insisto na necessidade de devolver a formação de professores aos professores, porque o reforço de processos de formação baseadas na investigação só faz sentido se eles forem construídos dentro da profissão. Enquanto forem apenas injunções do exterior, serão bem pobres as mudanças que terão lugar no interior do campo profissional docente".

A "investigação", da qual trata Nóvoa, retoma a questão do contexto. A capacitação de professores deve se dar em função das inquietações advindas da prática docente: os problemas com dificuldades de aprendizado, as dúvidas em relação as práticas pedagógicas, as incertezas sobre as metodologias de avaliação e as inseguranças no uso das TDs como ferramentas de apoio ao processo de aprendizagem.

Considerando a heterogeneidade do corpo docente de uma instituição educacional, haverá aqueles que já conseguiram superar algumas destas dificuldades, e que podem, de forma colaborativa, auxiliar os colegas. Entretanto, por questões diversas, o encontro entre estas pessoas não ocorre tão frequentemente quanto o desejado, o que dificulta a identificação dos interesses em comum, a troca de experiências e o compartilhamento de informações.

Uma alternativa a esta situação é oferecer aos professores a possibilidade de se reunirem de forma independente de local e horário. Para isso, o espaço virtual se presta como ponto de encontro para uma comunidade de prática docente onde, especificamente no contexto da cultura digital, pode-se não apenas falar sobre TDs, mas vivenciar o seu uso.

\section{A Experiência no IFRS-POA}

Em 2014 foi criado o programa de extensão "Comunidade de Prática em Inovação e Educação do IFRS, Campus Porto Alegre", com os seguintes objetivos:

- oferecer oportunidades de formação continuada para professores;

- desenvolver investigação sobre comunidades de prática docente; 
- oportunizar espaço de discussão sobre inovações em educação, em especial às relacionadas à cultura digital.

Com vistas a atingir o segundo objetivo, foi desenvolvido um estudo de caso. Essa metodologia é capaz de "proporcionar uma visão mais clara acerca de fenômenos pouco conhecidos [...]. Contribuem para a descrição de grupos, organizações e comunidades. [...]O que significa que os estudos de caso podem servir tanto a propósitos exploratórios quanto descritivos e explicativos" [8].

O estudo teve duração de seis (06) meses e foi desenvolvido no segundo semestre de 2014. Os participantes da CoP foram os professores do Instituto Federal de Educação, Ciência e Tecnologia do Rio Grande Sul - campus Porto Alegre, atuantes nos diversos cursos técnicos na modalidade subsequente, cursos de graduação e nos cursos de pós-graduação oferecidos pelo campus. $\mathrm{O}$ estudo de caso desenvolvido teve como técnica de coleta de dados a observação participante, a qual segundo Gil [8] consiste na "participação real do pesquisador na vida da comunidade, da organização ou do grupo em que é realizada a pesquisa. O observador assume [...] o papel de membro do grupo. Dai por que se pode definir observação participante como uma técnica pela qual se chega ao conhecimento da vida de um grupo a partir de seu próprio interior". A análise de conteúdo foi utilizada como técnica de análise de dados, uma vez que, segundo Minayo [12] uma das funções dessa técnica "diz respeito à descoberta do que está por trás dos conteúdos manifestos, indo além das aparências do que está sendo sendo comunicado". Durante o desenvolvimento desse estudo de caso, os pesquisadores compuseram o grupo de professores da instituição participantes da ação, atuando como mediadores e/ou coordenadores dos grupos de trabalho.

O modelo adotado pela Comunidade de Prática em Inovação e Educação do IFRS-Campus Porto Alegre foi híbrido, ou seja, além do espaço virtual, o grupo contou com a realização de encontros presenciais. Acredita-se que estes encontros fortaleceram os vínculos sociais, aumentaram a confiança e ajudaram a criar uma identidade de grupo, além de aumentarem a probabilidade de partilha de experiências e posterior produção de conhecimentos.

Carbonell [3] afirma que "o maior grau de inovação, com um conteúdo realmente alternativo, se produz nos espaços formativos menos regulados normativamente e academicamente". De fato, a liberdade para criação e experimentação dentro do espaço criado pela comunidade de prática, propiciou a produção de artigos, a elaboração e oferta de cursos de extensão e a experimentação de novas metodologias, voltadas para o aprimoramento da educação profissional.
Em relação a estrutura organizacional da Comunidade de Prática em Inovação e Educação do IFRS, campus Porto Alegre, dois papéis se destacaram: o mediador, responsável por motivar os participantes da comunidade e por mantê-la em movimento; e o coordenador, que faz a interface com a direção da instituição e é responsável por obter, junto a coordenação de ensino, espaço para os encontros presenciais, o fornecimento de certificados de participação, a disponibilização dos recursos computacionais necessários, entre outros. Uma peculiaridade observada, foi a segmentação da comunidade, em função de temas de interesse.

\section{1 - Grupo sobre o uso dos tablets educacio- nais}

Os professores participantes desse grupo foram os proponentes do programa de extensão "Comunidade de Prática em Inovação e Educação do IFRS, Campus Porto Alegre". Esse grupo se formou a partir da chegada dos tablets educacionais, entregues pelo governo federal por meio do Projeto Educação Digital - política para computadores interativos e tablets. Esse grupo tinha por objetivo discutir sobre as possibilidades de uso dos tablets e, posteriormente, das tecnologias móveis em geral, no contexto educacional. Este foi o grupo mais atuante da comunidade. Além do maior número de interações nos fóruns, em comparação com os demais grupos, produziu significativa quantidade de material. Conforme pode ser observado através da Figura 1, foram criados e disponibilizados: seleção de aplicativos (Apps) com uso educacional, vídeos e links relacionados ao uso de tecnologias móveis na educação. Além disso, foram oferecidas duas oficinas sobre o uso de Apps.

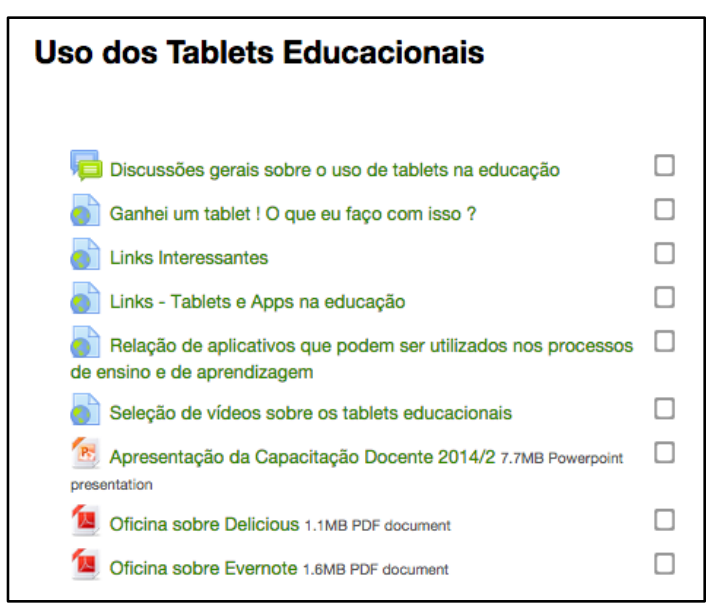

Figura 1 - Área do grupo "Uso de Tablets Educacionais", dentro do ambiente Moodle 


\section{2 - Grupo sobre projetos de aprendizagem}

Esse grupo tinha por objetivo discutir a metodologia de aprendizagem baseada em projetos, uma vez que a maioria dos cursos do IFRS-POA possui em seu currículo uma disciplina chamada "Projeto Integrador", que visa promover a articulação de conhecimentos de forma interdisciplinar. Entretanto, como mostra a Figura 2, o grupo acabou focando no estudo de uma nova proposta de metodologia para projetos de aprendizagem, baseada na metodologia ágil Scrum.

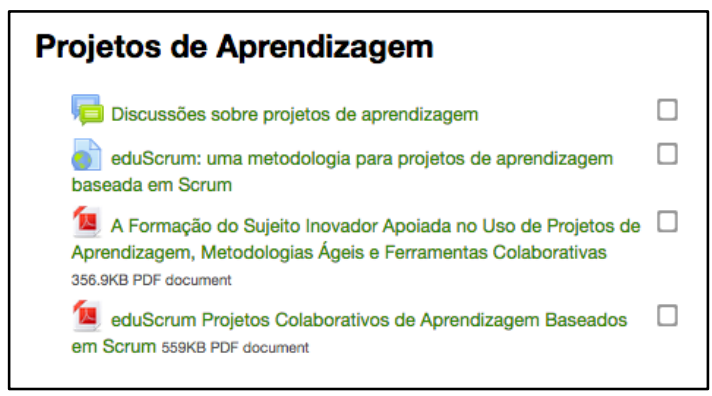

Figura 2 - Área do grupo "Projetos de Aprendizagem", dentro do ambiente Moodle

\section{3 - Grupo sobre hábitos de estudo}

Esse grupo surgiu a partir da preocupação dos professores da área de informática com o desempenho dos alunos. Sabendo-se que este é uma população de estudantes com características bem peculiares, o grupo tinha por objetivo identificar hábitos e métodos de estudo, a fim de propor atividades de extensão que ajudassem a melhorar o processo de aprendizagem dos alunos da área. A figura 3 apresenta a relação de conteúdo produzido pelo grupo.

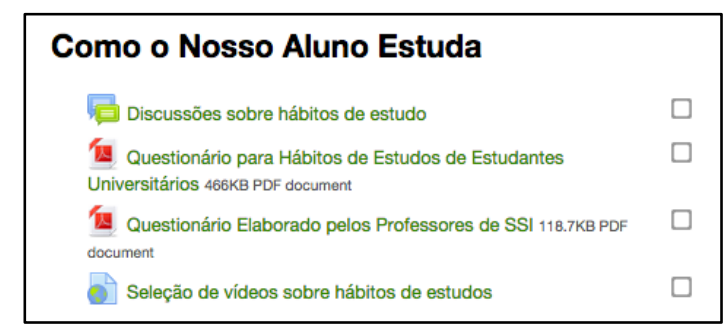

Figura 3 - Área do grupo "Como o Nosso Aluno Estuda", dentro do ambiente Moodle

\section{4 - O suporte computacional utilizado}

Considerando a familiaridade dos professores com o ambiente Moodle, este pareceu ser uma escolha natural para a construção do habitat digital da comunidade. Assim, foi criada uma sala virtual dentro do Moodle institucional, o qual, por sua natureza, já oferece os recursos apresentados na seção anterior deste artigo
Observando os conteúdos disponibilizados por cada subgrupo, é possível constatar a variedade de ferramentas utilizadas pelos membros da comunidade e associadas ao ambiente do Moodle:

- Pinterest: utilizado como um mural de imagens. No caso do link "Relação de aplicativos que podem ser usados nos processos de ensino e aprendizagem", o aplicativo foi utilizado para disponibilizar o ícone de cada App e links para tutoriais.

- Delicious: utilizado para organizar e compartilhar endereços da web. Em "Links - tablets e apps na educação" é disponibilizado o resultado de uma seleção de endereços cadastrados como favoritos e relacionados às palavras-chave "tablet", "educação" e "mobile learning".

- Youtube: utilizado para organizar e compartilhar videos. O link "Seleção de video sobre os tablets educacionais" redireciona para o canal pessoal de um do membros da comunidade, que pesquisou e organizou uma seleção de videos com tutoriais e reportagens.

- Slideshare: utilizado para compartilhar apresentações. Ao clicar em "Ganhei um Tablet ! O que eu faço com isso ?" O usuário sera redirecionado ao serviço de compartilhamento de slides, podendo visualizar, comentar e até mesmo baixar a apresentação.

- GoogleForms: utilizado para desenvolver o questionário sobre hábitos de estudos. O link "Questionário Elaborado pelos Professores de SSI" é um pdf gerado a partir da impressão do formulário do GoogleForms.

Essa busca por aplicativos e serviços "na nuvem" que complementassem os recursos oferecidos pelo Moodle, provam que a criação e configuração do habitat digital da comunidade pode se tornar uma das "práticas" desta comunidade

\section{Contribuições Desse Experimento}

A partir da análise dos dados produzidos durante os seis meses de duração do programa de extensão "Comunidade de Prática em Inovação e Educação do IFRS, Campus Porto Alegre" pode-se observar que a CoP criada e seus grupos de trabalho eram compostos por professores de diversas áreas do conhecimento, e por conta dessa característica, a CoP proporcionou oportunidades de formação continuada para além dos conteúdos específicos das disciplinas ministradas por cada um dos participantes. 
A partir das experiências desenvolvidas pela $\mathrm{CoP}$, com a experimentação das TDs em um ambiente híbrido de trabalho colaborativo, bem como de aprendizagem colaborativa, foi oportunizada uma "experiência vivida" de adoção de habitats digitais para a comunicação entre os participantes de um grupo de trabalho, para a disponibilização e consulta de conteúdos por meio de repositórios, e para a participação em produções colaborativas de materiais. Com essas características a $\mathrm{CoP}$ viabilizou um espaço de experimentação e discussão das TDs como ferramentas que superam a mera condição de suporte à transmissão de conteúdos. Além disso, pode-se destacar alguns aspectos formalizáveis desse estudo:

1. O sucesso de uma comunidade de prática docente depende da criação, por parte da instituição de ensino, de uma cultura de formação continuada e avaliação contínua do corpo docente. Essa pode ajudar o professor a identificar suas fraquezas que, com a troca de experiências com outros docentes, podem ser trabalhadas e superadas.

2. Por si só as TDs não são capazes de alterar as práticas humanas. Principalmente em relação a profissão de professor, que possui história e práticas centenárias, passadas de geração para ção. Assim, faz-se necessário um trabalho de quebra de paradigmas com vistas a mudança na relação professor-aluno-conhecimento.

3. O aprimoramento profissional apenas será efetivo quando o professor conseguir aplicar em sala de aula os conhecimentos, metodologias, tecnologias e demais questões trabalhadas dentro da comunidade. Para isso é necessário que o professor esteja disponível, não apenas em função do tempo a ser dedicado à comunidade, mas também em relação a abertura as novas ideias.

4. Há a necessidade de mudança de postura do professor. "O professor pode se apropriar de técnicas novas, de algumas práticas, mas se a atitude básica não for alterada, estará desvirtuando o trabalho" [19]. Espera-se, então, que o professor que participa de uma comunidade de prática docente desenvolva características empreendedoras, tais como criatividade, pró-atividade, capacidade de gerenciar imprevistos e de buscar a inovação. Entretanto, é importante destacar que a inovação desejada não é aquela que apresenta o velho com roupagem nova. Deseja-se, sim, que ela promova a criatividade, o pensamento reflexivo, as novas formas de aquisição e construção do conhecimento.

\section{Considerações Finais}

Algumas inovações puderam ser observadas como resultado das práticas da Comunidade de Prática em Inovação e Educação do IFRS, Campus Porto Alegre. Por exemplo, o uso de metodologias de gerenciamento de projetos como forma de promover a auto-regulação da aprendizagem [1]. Além disso, foram relatados o uso de Apps para o ensino de Química, de criação de grupos de discussão através do Facebook e de utilização do aplicativo Evernote para a elaboração de diários de bordo.

A partir disso, somos levados a concordar com Carbonell [3] quando este diz que "as inovações que vem de baixo, do próprio coletivo docente tem mais possibilidade de êxito e continuidade do que aquelas que emanam de cima", pois é a iniciativa do professor, por exemplo em busca de formas alternativas de atualização profissional, tais como as comunidades de prática, que irá servir de modelo para que colegas seus também se engajem neste processo de inovação na educação.

Como trabalhos futuros, propomos replicar esta experiência através da criação de uma comunidade de prática virtual inserida em um curso de formação de professores à distância. No contexto de um curso deste tipo, a comunidade poderá favorecer a interação entre os participantes do curso, promovendo a troca de conhecimentos. Tanto os conhecimentos produzidos dentro do curso, como aqueles obtidos a partir da experiência profissional de cada um. Além disso, e principalmente, espera-se que uma experiência desse tipo seja capaz de produzir um novo conhecimento, que contribua com as inovações na educação.

\section{Referências}

[1] BORGES, K. S. ; MORAES, M. A. C. ; OKUYAMA, F. Y. Autorregulação da Aprendizagem em Computação Com Apoio do Scrum. In: Revista Texto Livre, v. 6, p. 5. 2003.

[2] CAMBRIDGE, D.; KAPLAN, S.; SUTER, V. Community of Practice Design Guide: A Stepby-Step Guide for Designing \& Cultivating Communities of Practice in Higher Education. 2005.

http://net.educause.edu/ir/library/pdf/nli0531.pdf Outubro/2015.

[3] CARBONELL, J. A Aventura de Inovar: a mudança na escola. Porto Alegre: Artmed. 2002. p. 28 
[4] CLAXTON, G. O Desafio de Aprender ao Longo da Vida. Porto Alegre: Artmed. 2005. p. 221.

[5] CONNECTED EDUCATORS. Technology for Online Communities of Practice. 2011.

http://connectededucators.org/wpcontent/uploads/2011/03/0143_Platforms-andTools-march-2011.pdf. Junho/2015

[6] COSTA, R. M. M. at. al. Comunidades de Prática e ferramentas Web 2.0: uma experiência em um curso de especialização em Matemática. In: Anais do XV Workshop sobre Informática na Escola. XXIX Congresso da Sociedade Brasileira de Computação. Bento Gonçalves, 2009.

[7] ESTEVES, M. at. al. Uso do Second Life em Comunidade de Prática de Programação. In: Revista Prisma.com, n. 6. 2010.

[8] GIL, A. C. Estudo de Caso: fundamentação científica, subsídios para coleta e análise de dados, como redigir o relatório. São Paulo: Atlas, 2009. p. 74.

[9] ILLERA, J. L. R. Como as comunidades virtuais de prática e de aprendizagem podem transformar a nossa concepção de educação. In: Sísifo - Revista de Ciência da Educação, $\mathrm{N}^{\mathrm{o}}$ 3. Maio/Ago 2007.

[10] IMBERÓN, F. Formação Permanente do Professorado: novas tendências. São Paulo: Cortez, 2009. p. 52.

[11] MENGALLI, N. M. Conceitualização de Comunidade de Prática (CoP).

http://sites.google.com/site/proalexandre/Conceit ualizaodeComunidadedePrtica.doc. Outubro/2015.

[12] MINAYO, M. C. S. (org.); DESLANDES, S. F.; NETO, O. C.; GOMES, R. Pesquisa Social:

Teoria, método e criatividade. 26. ed. Petrópolis, RJ: Vozes, 2007. p.74

[13] MORETTO, T. Para viver em comunidade não é preciso estar perto. In: Adital: noticias da América Latina e Caribe. Junho de 2014.

[14] NÓVOA, A. Os professores e a sua formação. Lisboa: Dom Quixote. 1992

[15] NÓVOA, A. Para uma formação de professores construída dentro da profissão. In: Revista de Educación, 350. Septiembre-diciembre 2009, p. 203-218.

[16] OLIVEIRA JR, D. A. de. Comunidades de Prática: um estudo dos grupos de usuários Java brasileiros. Dissertação de Mestrado do Programa de Pós-Graduação em Gestão do Conhecimento e da Tecnologia da Informação. Universidade Católica de Brasília, 2005.

[17] ROCHA, M. A. P. Comunidades virtuais de prática: contextos educacional, profissional e sociedade civil. Tese de Doutorado em Educação. Universidade Aberta, Lisboa, Portugal, 2013.

[18] SMITH, M. K. Jean Lave, Etienne Wenger and communities of practice, the encyclopedia of informal education.

http://www.infed.org/biblio/communities_of_pra ctice.htm. Acesso em outubro de 2015.

[19] VASCONCELLOS, C. S. Para onde vai o professor? Resgate do professor como sujeito de transformação. São Paulo: Libertad, 2014. p. 156 